leaves the mercurial surface, and generally bursts in doing so.

Considerable impurities in the mercury do not render the production of these bubbles impossible. Very stable bubbles may be formed of mercury contaminated with sodium. But the most stable have been formed from mercury recently cleaned with dilute nitric acid followed by a solution of caustic potash.

Another striking and beautiful experiment with the production of these bubbles may be made by directing a strong jet of water into a shallow vessel containing some mercury. The stream of water, carrying air bubbles with it, penetrates the supernatant water and impinges on the mercury below. There it forms numerous bubbles of various sizes contained in mercury pellicles, many of which detach themselves from the mercury below, and are carried about iin the water. The stability of these bubbles is amazing. They are often whirled round and round in the turbulent motion of the water for several seconds without bursting.

Henry H. Dixon.

Botanical Laboratory, Trinity College, Dublin.

\section{Radium Fluorescence.}

IF a tube containing radium bromide is wrapped in black paper and brought within three or four inches of the eye, in a dark room, a curious sensation of general illumination of the eye is experienced; this occurs whether the eyelid is closed or not. It is difficult accurately to describe the sensation produced; the eye seems filled with light. This effect can readily be detected when six florins are placed between the closed eye and the sample of radium.

Probably the effect is due to general fluorescence of every part of the eye, for fluorescence seems to be a commoner property of matter than hitherto suspected.

The following substances are distinctly fluorescent under radium radiation :-

$\begin{array}{lll}\text { Opal Glass. } & \text { Quartz. } & \text { Human Skin. } \\ \text { Soda Glass. } & \text { Sulphur. } & \text { Human Nails. } \\ \text { Lead Glass. } & \text { Sugar. } & \text { Camphor. } \\ \text { Uranium Glass. } & \text { Starch. } & \text { Cetaceum. } \\ \text { Didymium Glass. } & \text { Fluor Spar. } & \text { Solid Paraffin. } \\ \text { Celluloid. } & \text { Yellow Resin. } & \text { Liquid Paraffin. } \\ \text { Mother of Pearl. } & \text { Cotton Wool. } & \text { Turpentine. } \\ \text { Mica. } & \text { White Paper. } & \text { Chloroform. } \\ \text { Borax. } & \text { Cupri Sulph. } & \text { Water. } \\ \text { Alum. } & \text { Quinine Sulph. } & \text { Glycerin. }\end{array}$

I have been unable to detect decided fluorescence in the following substances, however, with a more powerful source of radiation, or a more sensitive receiver than the eye; possibly some of these might be placed in the first.list :-

Potass Bichrom.

Ruby Glass (flashed).

Prepared Chalk.

Ebonite.

Silk.

Selenium

Plaster of Paris.

Iodosulphate of Quinine.

Woods (various)

Camphor Monobromate.

In the case of translucent substances, the effects are best observed by looking through the substance, placing the tube of radium nearly in contact with the far side. If the experiments are carried on too near the eye, the direct fluorescence of the eye itself interferes with accurate observations.

Little cups made of thick tinfoil are very convenient for the examination of liquids; the open vessel is viewed from above, the radium being placed below the cup.

It is important to well prepare the eye by excluding every trace of light from the room for at least a quarter of an hour before the experiments are made.

r56 Clapham Road, S.W., June x.

\section{F. HARRISON GLEW.}

\section{A New Series in the Magnesium Spectrum}

IN your issue of April 16 there is an abstract of a paper communicated by Prof. Fowler on the above subject to the Royal Society. He shows that his new series is of the same type as the special series for magnesium discovered by Rydberg, and represents it by a similar formula to that used by Rydberg. But in "The Cause of the Structure of NO. I 757 , vOL. 68]
Spectra" (Phil. Mag., September, I9oI) I have shown that the Rydberg series for magnesium can be represented by a formula which brings out the existence of harmonics in atomic vibrations. These can be demonstrated in the hydrogen spectrum also, but it seemed to be of interest to inquire whether the new series gives a further example of the existence of optical harmonics. It does, for the vibration numbers of its four lines can be given by the formula

$$
n=39730-\frac{107250}{(2 \cdot 977-2 \cdot 021 / s)^{2}}
$$

where $s$ has the values $4,5,6$ and 7 .

This may be written approximately as

$$
n=39730-\frac{107250}{\{3-0.023-(2+0.023) / s\}^{2}}
$$

while Rydberg's special series is represented by

$$
n=39730-\frac{107250}{(3-2 \cdot 343 / s)^{2}} .
$$

I have not thought it worth while to test whether the harmonic formula for the new series is as successful as Rydberg's in giving the wave-lengths accurately, as the evidence for the existence of optical harmonics is what I wish to draw attention to. In Rydberg's series $s$ has all the integral values from 3 to 8 . In the new series Prof. Howler gives wave-lengths for which $s$ has integral values from 4 to 7 . We might expect the lines for $s=3$ and $s=8$ to be yet found. Their wave-lengths by the harmonic formula would be 5125.8 and $3956 \cdot 3$.

Melbourne, May 27.

William Sutherland.

\section{THE KITE COMPETITION OF THE AERONAUTICAL SOCIETY.}

THE kite competition for the silver medal of the Aëronautical Society of Great Britain took place on Thursday, June 25, on the Sussex Downs, at Findon, near Worthing, by permission of Lord Henry Thynne. The conditions specified that a weight of two pounds as representing the weight of recording meteorological instruments should be carried, and that the medal should be given for the highest flight attained by a single kite above 3000 feet. The altitude of the kites was to be determined by trigonometrical observations.

The locality proved to be admirably adapted for the competition under the conditions of weather prevailing at the time. A light wind from the south-west blew up the slope of the Downs in the morning, and increased to a steady breeze in the afternoon, backing somewhat to the southward as the day, which was beautifully fine, went on.

It was understood that observations of the altitude of the kites should be commenced after the lapse of an hour from the signal for starting. By 2.45 p.m. stations for the kite reels had bcen arranged, 200 yards apart, along the slope of the Downs, and two stations for the theodolites, 700 yards apart, were selected, from which the kite stations were visible, and which were likely to command an uninterrupted view of the kites during the flight. The responsible duty of carrying out the measurements with the theodolites and the auxiliary chaining was most kindly undertaken by Mr. J. E. Dallas and Mr. W. F. Mackenzie, of the Royal Indian Engineering College, Coopers Hill, and the success of the arrangements was due in no small degree to the assistance afforded by these gentlemen.

At 2.45 the signal was given to start, and at 3.45 observations of height commenced. The synchronism of the observations of any particular kite from the two stations was secured at first by a prearranged code of signals from one theodolite station to the other, and subsequently by telephone between the two stations. Eight kites were entered for the competition, but only six appeared on the ground, and only 